\title{
Oral Ascorbic Acid And $\alpha$-Tocopherol Protect On Di-(2-Ethyl Hexyl) Phthalate (DEHP) Induced Effects On Gonadotoxicity In The Adult Male Wistar Rats
}

\author{
S. A. Ogli, S. O. Odeh
}

\begin{abstract}
Environmental pollutants such as di-(2ethylhexyl) phthalate (DEHP) adversely affect reproductive system tissue differentiation and functions with exposure at intrauterine, neonatal or adult stages of life, thereby potentiating male infertility later in life. World health organization estimates a global infertility prevalent rate of 10 $15 \%$, and $20-30 \%$ among Nigerians, with male factor constituting about $40-50 \%$ of infertility cases. This study was designed to investigate the effect(s) of oral vitamins $C$ and $E$ on DEHP induced changes in some semen parameters and serum testosterone concentration in adult Wistar rats. Seventy (70) adult male Wistar rats weighing between 156-250 $\mathrm{g}$ were randomised into 7 experimental groups $1,2,3,4,5,6$ and 7 (group $n=10$ ). Animals in groups 1,2 and 3 were treated with $0.02 \mathrm{mg}, 20 \mathrm{mg}, 200 \mathrm{mg}$ oral DEHP/kg bw daily respectively, while those in groups 4,5 and 6 , in addition to the above DEHP treatments, were treated with $100 \mathrm{mg}$ ascorbic acid and $67.5 \mathrm{mg} \alpha$-tocopherol per $\mathrm{kg}$ bw daily respectively. Rats in group 7 served as Control and were treated with vehicle. All treatments lasted for 60 days. After, over night fasting, samples of semen and serum were obtained for analysis. Results obtained were expressed as mean \pm standard deviation and analyzed for significant differences in means using one way ANOVA and Post Hoc test. Relative to the control reference values, groups exposed to oral DEHP had significant $(p<0.05)$ reduction in sperm count, total sperm motility, active sperm motility, normal sperm morphology, serum testosterone concentration and serum super oxide dismutase levels to $31.70 \pm 18.68 \times 106 \quad$ cells $/ \mathbf{m L}, \quad 38.60 \pm 24.78 \%, \quad 8.50 \pm 5.66 \%$, $38.00 \pm 18.00 \%, \quad 9.56 \pm 1.34 \mathrm{ng} / \mathrm{mL}$ and $0.017 \pm 0.0013$ units respectively. Sluggish sperm motility and abnormal sperm morphology significantly $(p<0.01)$ increased to $39.70 \pm 13.05 \%$ and $68.50 \pm 18.42 \%$ respectively. In the groups that had DEHP co-treatments with oral ascorbic acid and $\alpha$-tocopherol, all studied parameters tended to comparative indifference statistically, with the Controls values. This indicates a protective function against DEHP effects on the studied parameters. The study has shown therefore, that DEHP inflicts oxidative stress in the reproductive system which potentially suppresses serum testosterone concentration with attendant derangements in the qualitative and quantitative sperm cells in adult Wistar rats, and thereby enhancing male infertility. However, the antioxidants ascorbic acid and $\alpha$-tocopherol protects the gonadal and sperm cells from the harmful effects of DEHP by ameliorating oxidative stress and improving male fertility. This implies that there is need to avoid prolonged exposure to DEHP while encouraging the daily intake of oral ascorbic acid and $\alpha$-tocopherol.
\end{abstract}

Index Terms - Antioxidant, ascorbic acid and $\alpha$-tocopherol, Di-(2-ethylhexyl) phthalate, male infertility.

Published on June 24, 2020.

S. A. Ogli, Benue state University, Nigeria.

(corresponding e-mail: saogli@live.co.uk).

S. O. Odeh, University of Jos, Nigeria.

\section{INTRODUCTION}

With the dawn of industrialization, fertility in man generally has been on the decline, attributed not just to social and biological factors such as changes in conceptive practices, diminished sexual activity or infective causes alone, but to observed poor semen quality among healthy young men [1]. Globally, the incidence of infertility has assumed an alarming proportion over the past three decades with a possible rising trend, despite the availability of new diagnostic and treatment facilities [2]. World health organization (WHO) estimates that sixty (60) to eighty (80) million couples globally currently suffer from infertility [3]. In sub-Saharan Africa, the infertility rate varies widely from region to region; between $9 \%$ to $21.2 \%$ [4]-[6]. In Nigeria however, the prevalence rate is about 26-43\% [7]. A Nigerian study has shown that male factor infertility factor constitute about $25-40 \%$ of infertility cases [8], though the figure may vary from one part of the country to the other as an earlier study in the Northern part of the country suggested a male infertility rate of about $50 \%$ (Panti \& Sununu, 2014).

The emergence of none infective aetiology of male infertility is gaining increasing medical and gynaecological importance in clinical diagnosis. [10] observed that male infertility arising from absence of clinical causes (idiopathic infertility) may be due to exposure to environmental toxicants that alter spermatogenesis or sperm function. Di(2-ethylhexyl) phthalate (DEHP), otherwise called bis-(2ethylhexyl) phthalate (BEHP) or di-octyl phthalate (DOP), the most common plasticizer in polyvinyl chloride (PVC) or plastic. DEHP has been implicated in diverse forms of male gonadotoxicity [11], [12], and has been identified in the blood, urine, and semen of exposed men, possibly affecting sperm quality [13] as it has been incriminated in the direct impairment of spermatogenesis and spermatozoa deoxyribonucleic acid (DNA) defects due to its ability to induce oxidative stress (OS) in gonadic tissues [14]. In humans, DEHP exposure has profound effect on endocrine and reproductive systems, especially in early phases of life [15]. DEHP metabolite measured from the blood of exposed pregnant women has been significantly associated with reduced penis width, shorter anogenital distance, incomplete testicular descent, and shorter pregnancy durations; a replication of effects identified earlier in animals [16]. Demonstrated toxicity in rat and mice studies included decreased in fertility, proportion of pups born alive and testicular weights as well as tubular atrophy [17].

Spermatozoa are highly susceptible to reactive oxygen 
species (ROS), which are key intermediates in cellular signal transduction pathways, whose actions may be counterbalanced by antioxidants [18], a role mediated by Bmi1, the polycomb repressor universally expressed in all types of testicular cells. Bmil deficiency resulted in ROS accumulation and tissue oxidative damage including DNA damage [19]. Ascorbic acid (AA) and $\alpha$-tocopherol ( $\alpha$-TCP) are highly effective antioxidant in humans and in other living organisms, acting to protect the body by lessening oxidative stress, with widespread use in ameliorating the toxic effects of radicals on cells and tissues [20], [21] and strengthening the body's natural antioxidant machinery to avert ROS-induced injuries. Synergy between AA and $\alpha$ TCP helps protect spermatozoa from damages induced by oxidative stress [22], [23]. They have been shown to correct gonadotoxicity that manifested as derangement of semen indices in laboratory animals [24], [25], as well as exhibiting a therapeutic effect on DEHP-induced aspermatogenesis in humans [26].

Consequently, this study was designed to investigate the protective effect of oral AA and $\alpha$-TCP on oral DEHP induced reproductive drangements in the adult male Wistar rats. It is hoped that the study will provide an insight into one of the major ways of alleviating idiopathic male infertility and hence enable preventive measures to be proffered by the key actors in reproductive medicine.

\section{Materials And Methods}

\section{A. Animal procurement and treatment}

Seventy (70) healthy reproductively matured male albino Wister rats weighing between 156-250 g (mean weight of $175 \mathrm{~g}$ ) were procured from the Animal house, of the College of Health Sciences, Benue State University for the study and randomised into 7 experimental blocks $1,2,3,4,5,6$, and 7 (group $\mathrm{n}=10$ ). The animals were housed in locally constructed wooden cages with wood chip beddings, acclimatized for two weeks and maintained in a controlled environment with a $12 \mathrm{hr}$ light/dark cycle, temperature of $30 \pm 2{ }^{\circ} \mathrm{C}$ and relative humidity of $60 \pm 18 \%$. The animals were exposed to free growers chow and water ad libitum. Care of the rats was consistent with international animal care regulations [27].

DEHP (Sigma-Aldrich $\left.{ }^{\circledR}\right)$, ascorbic acid (Em-vit-C ${ }^{\circledR}$ ) and $\alpha$-tocopherol (Good'N Natural ${ }^{\circledR}$ ) were procured from reputable company outlets respectively and administered as follows:

Group 1: $0.02 \mathrm{mg}$ DEHP/kg bw [28].

Group 2: $20 \mathrm{mg}$ DEHP/kg bw [28].

Group 3: $200 \mathrm{mg}$ DEHP/kg bw.

Group 4: 0.0 2mg DEHP with 100mg ascorbic acid [29], [30] and $67.5 \mathrm{mg}$ (150 IU) $67.5 \mathrm{mg}$ (150 IU) $\alpha$-tocopherol [31], [32] per kg bw.

Group 5: $20 \mathrm{mg}$ DEHP with 100mg ascorbic acid [29], [30] and $67.5 \mathrm{mg}$ (150 IU) $67.5 \mathrm{mg}$ (150 IU) $\alpha$-tocopherol [31], [32] per kg bw.

Group 6: $200 \mathrm{mg}$ DEHP 100mg ascorbic acid [29], [30] and $67.5 \mathrm{mg}$ (150 IU) $67.5 \mathrm{mg}$ (150 IU) $\alpha$-tocopherol [31], [32] per kg bw.

Group 7: Control.
All treatments were administered intrapharyngeally daily for 60 days. On day 61 and after an overnight fast, the animals were observed for general physical activity, mobility/agility and anesthetized with inhalational chloroform. Cardiac puncture was performed [33] to aspirate $3 \mathrm{ml}$ of fasting blood into a plain, clean blood sample bottle for assay of serum testosterone concentration and SOD level. Through a clean incision and careful dissection, a testis (selected randomly) was harvested into a test tube containing $0.1 \mathrm{ml} 0.95 \%$ saline solution for semen analysis.

\section{B. Semen analysis}

Semen was harvested from the caudal region of the epididymis by milking in $0.1 \mathrm{~mL} 0.95 \%$ saline solution was analyzed for count, motility and morphology using standardized method described by [34], and adapted in other studies [35] in accordance with the WHO semen analysis guideline.

\section{Testosterone assay}

Blood sample collected was allowed to stand for 40 minutes and centrifuged at a speed of. Using a calibrated pipette, between 0.5 and $1 \mathrm{~mL}$ of the clear supernatant serum was aspirated into another plain clean blood sample bottle from where testosterone assay was conducted using standard enzyme linked immune sorbent assay (ELISA) technique (AccuBindTM Elisa microwell testosterone test system kit, product code 3725-300). The result was read using the Stat fax-2100 microplate reader (Awareness Technology ${ }^{\mathrm{TM}}$ ).

\section{Serum Superoxide Dismutase (SOD) Assay}

Superoxide dismutase (SOD) assay was carried out using the technique described by [37] and adapted by [38]; utilising the rapid auto-oxidation of pyrogallol in aqueous or alkaline medium solution (as typified by Tris buffer at $\mathrm{pH}$ of 8) as the underlinig principle. The degree of oxidation of pyrogallol is read at a particular wavelength using spectrophotometer. SOD, as an antioxidant, inhibits this auto oxidation of pyrogallol. Therefore, the levels of SOD in the sample serum will inversely correlate with the oxidizing pyrogallol.

\section{E. Statistical analysis}

Data obtained expressed as mean $\pm \mathrm{SD}$, were entered into Microsoft ${ }^{\circledR}$ office excel spread sheet version 2010 and analyzed with excel spread sheet Qi Macros 2013. One way analysis of variance (ANOVA) was employed to test significant differences between and within group means. Ftest was used to determine levels of significant variation in means at probability level of 0.05 . Where significant differences exist among mean, Post Hoc test was applied to define specific group with mean differences.

\section{RESUlTS}

Results obtained from the study at the end of treatment indicated that the parameters studied were adversely affected in the adult Wistar rat on exposure to oral DEHP, but ameliorated with the co-administration of ascorbic acid and $\alpha$-tocopherol. 


\section{A. Sperm count}

Fig. 1 shows the response of sperm count to DEHP, AA and $\alpha$-TCP treatments. There was significant reduction $(\mathrm{p}<0.01)$ in mean sperm count in groups 1,2 and 3 due to DEHP treatments to $53.80 \pm 12.10, \quad 31.70 \pm 18.68$ and $67.70 \pm 15.30$ million cells $/ \mathrm{mL}$ respectively relative to $115.10 \pm 15.95$ million cells $/ \mathrm{mL}$ of group 7 . Effect of oral cotreatments with these antoxidants in groups 4,5 and 6 significantly $(p<0.01)$ increased the mean sperm counts from values observed in groups 1,2 and 3 respectively to $132.30 \pm 33.15, \quad 88.60 \pm 43.93$ and $117.20 \pm 26.56$ million cells/ml, corresponding to a $2.5,2.8$ and 1.7 folds increases respectively. These increases were not significantly different from the value of the Control group, implying that oral exposure to DEHP induces oligospermia; a condition that was reversed by co-treatment with oral AA and $\alpha$-TCP in the adult Wistar rats.

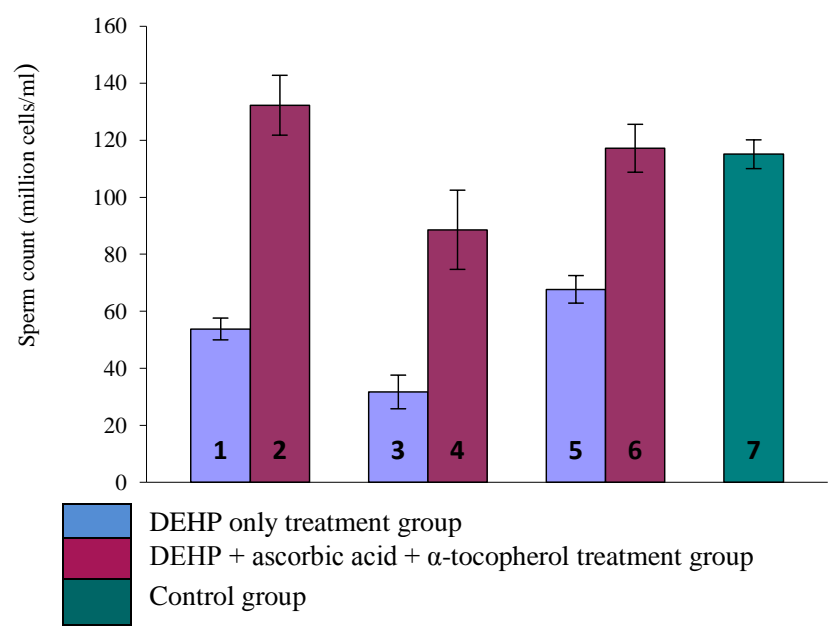

Fig. 1. Suppressive effect of oral DEHP exposure and protective effect of oral ascorbic acid and $\alpha$-tocopherol on Sperm count in adult Wistar rats.

\section{B. Sperm motility}

Fig. 2 shows the effect of oral DEHP on total sperm motility, which was reduced significantly $(\mathrm{p}<0.05)$ to $38.60 \pm 24.78 \%$ only in group 2 from $83.20 \pm 8.42 \%$ in the Control group (a 2.2 fold reduction). There was no statistical difference in mean of total sperm motility of groups 1 and 3 compared to the Control group respectively. AA and $\alpha-$ TCP oral co-treatments with DEHP significantly $(\mathrm{p}<0.01)$ increased the mean total sperm motility to $94.00 \pm 3.72 \%$ and $82.54 \pm 8.97 \%$ in groups 4 and 5 respectively, relative to groups 1 and 2 on the one hand and in group 4 relative to the Control on the other hand.

In Fig. 3, active sperm motility was reduced significantly $(\mathrm{p}<0.05)$ only in groups 1 and 2 to $32.10 \pm 13.66 \%$ and $8.50 \pm 5.66 \%$ respectively from $61.40 \pm 12.88 \%$ of Control group. This reduction was comparatively more profound in group 2. Co-treatment with oral AA and $\alpha$-TCP significantly $(\mathrm{p}<0.05)$ increased the mean active sperm motility in groups 4,5 , and 6 respectively compared to the values obtained in groups 1, 2 and 3. However, relative to the Control group, no significant increases in active sperm motility were observed in groups 4,5 and 6 , suggesting that AA and $\alpha$ TCP offers protection from the suppressive effect of DEHP on active sperm motility.

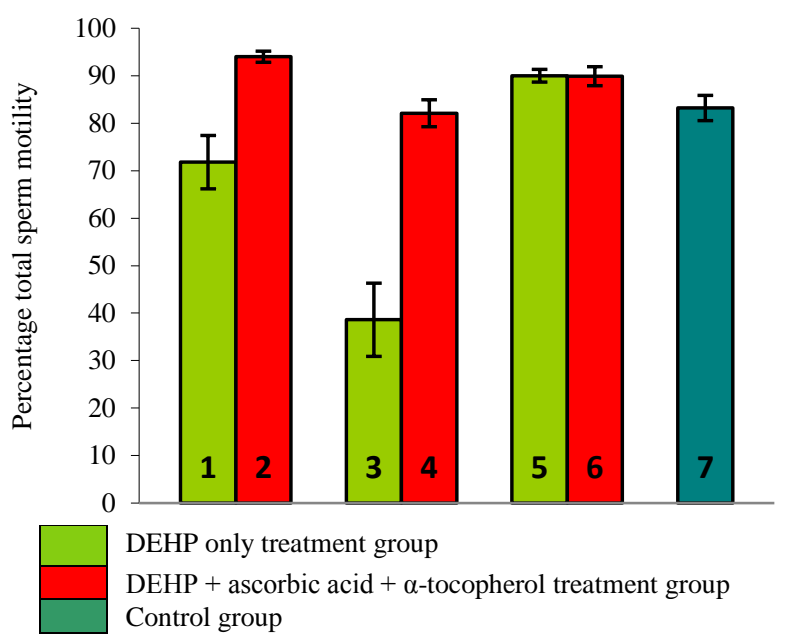

Fig. 2. Suppressive effect of oral DEHP exposure and the protective effect of oral ascorbic acid and $\alpha$-tocopherol on Total sperm motility in adult Wistar rats.

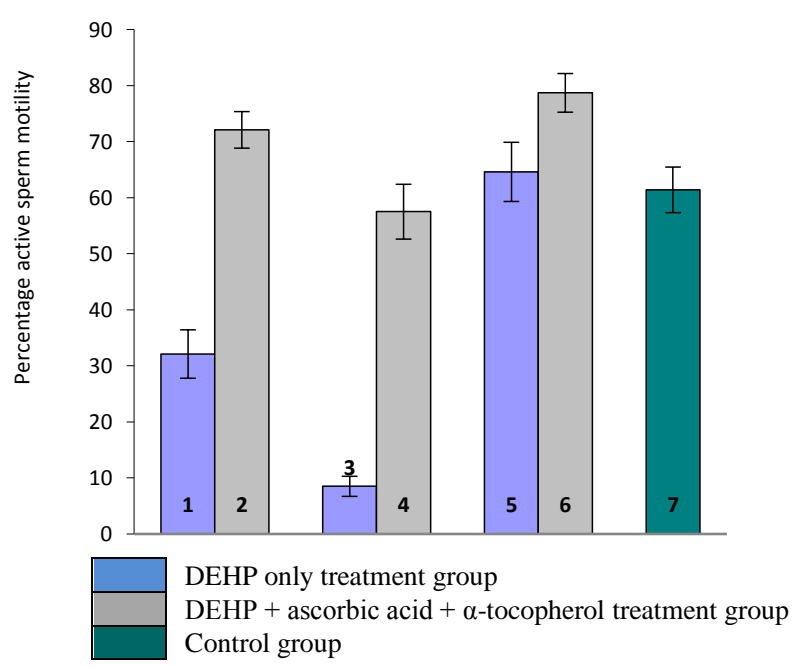

Fig. 3. Suppressive effect of oral DEHP exposure and protective effect of oral ascorbic acid and $\alpha$-tocopherol on Active sperm motility in adult Wistar rats.

In Fig. 4, the mean sluggish sperm motility in groups 1, 2 and 3 were $39.70 \pm 13.48 \%, \quad 30.30 \pm 25.77 \%$ and $25.40 \pm 17.39 \%$ respectively compared to $21.80 \pm 12.94 \%$ of the Control. This showed a numerical increase in the population of sluggishly motile/immotile spermatozoa, but significant increase was observed only in group 1 relative to the Control group. The mean sluggish sperm motility in groups co-treated with oral AA and $\alpha$-TCP along with oral DEHP were $21.90 \pm 9.93 \%, 24.60 \pm 11.35 \%$ and $11.20 \pm 6.76 \%$ respectively, indicating a significant $(\mathrm{p}<0.05)$ reduction in the mean sluggish sperm motility in groups 4 and 6 (by 1.8 and 2.3 folds) relative to groups 1 and 3 respectively; and in group 6 relative to Control group. There was no significant difference in means of sluggish sperm motility between groups 4 and 5, and that of the Control, indicating the opposing effect of these antioxidants against DEHP induction of sluggish motility. 


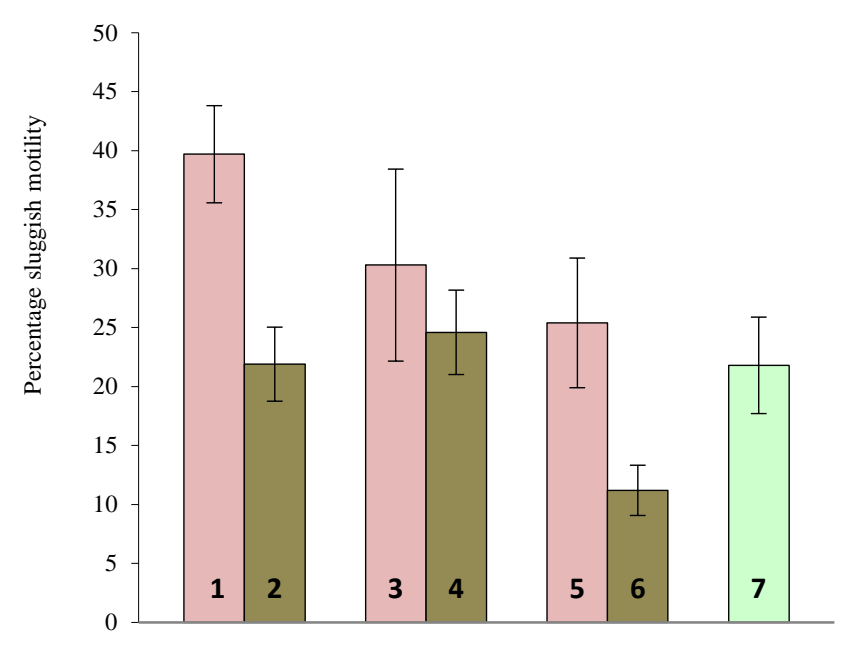

DEHP only treatment group

DEHP + ascorbic acid $+\alpha$-tocopherol treatment group Control group

Fig. 4. Inductive effect of oral DEHP exposure and supressive effect of oral ascorbic acid and $\alpha$-tocopherol on Sluggish sperm motility in adult Wistar rats.

\section{Sperm morphology}

In Fig. 5, the treatment effects of oral DEHP on sperm morphology were shown. Sperm cells with mean normal sperm morphology of $59.90 \pm 21.89 \%, 38.00 \pm 18.00 \%$ and $77.00 \pm 22.88 \%$ respectively in groups 1,2 and 3 . This indicated a significant $(\mathrm{p}<0.01)$ reduction $(1.8$ folds $)$ in normal sperm morphology in group 2 at $38.00 \pm 18.00 \%$ from $68.90 \pm 18.42 \%$ of the Control group. With oral AA acid and $\alpha$-TCP co-treatments in groups 4,5 and 6 , the mean normal sperm morphology was $71.00 \pm 32.13 \%, 66.30 \pm 18.27 \%$ and $76.60 \pm 11.19 \%$ respectively. While there was a significant increase $(\mathrm{p}<0.05)$ only in group 5 relative to group 2 , no statistical difference was observed in mean of normal sperm morphology between groups 4, 5 and 6 compared to group 7 (Control).

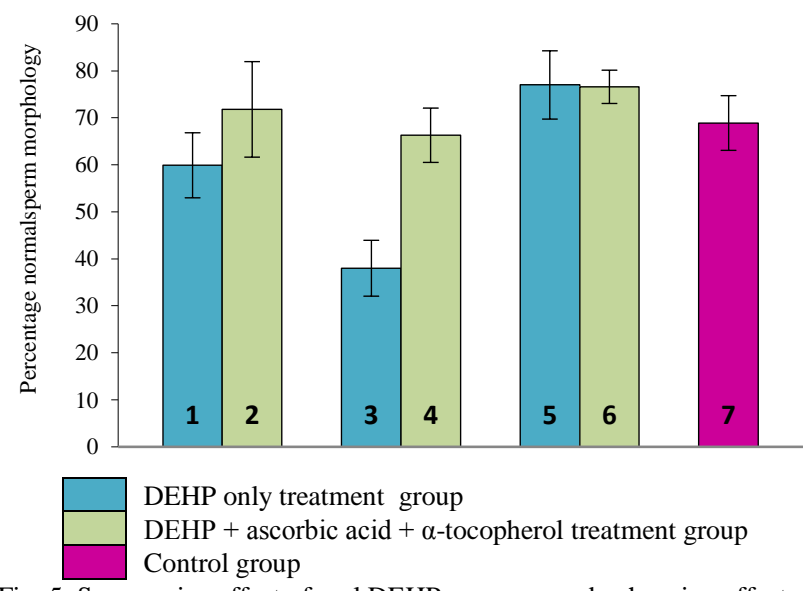

Fig. 5. Suppressive effect of oral DEHP exposure and enhancing effect of oral ascorbic acid and $\alpha$-tocopherol on normal sperm morphology in adult Wistar rats.

In Fig. 6, mean abnormal sperm morphology exposed to oral DEHP only were $40.10 \pm 21.89 \%, 62.00 \pm 18.80 \%$ and $23.00 \pm 22.88 \%$ in groups 1,2 , and 3 respectively, indicating a significant $(\mathrm{p}<0.05)$ increase (about 2 folds) only in group 2 , compared with $31.10 \pm 18.41 \%$ of Control group (7). In groups co-treated with oral AA and $\alpha$-TCP (4, 5 and 6), mean abnormal sperm morphology were $28.20 \pm 22.13 \%$, $33.70 \pm 18.27 \%$ and $23.40 \pm 11.18 \%$ respectively, showing a significant $(\mathrm{p}<0.05)$ reduction $(1.8$ fold $)$ in the population of cells with abnormal morphology in group 5 only.

These results indicate that exposure of the experimental animals to oral DEHP enhances the synthesis of sperm cells with abnormal morphology while co-exposure to the antioxidants improves sperm cell morphology (qualitative) even in the presence of DEHP.

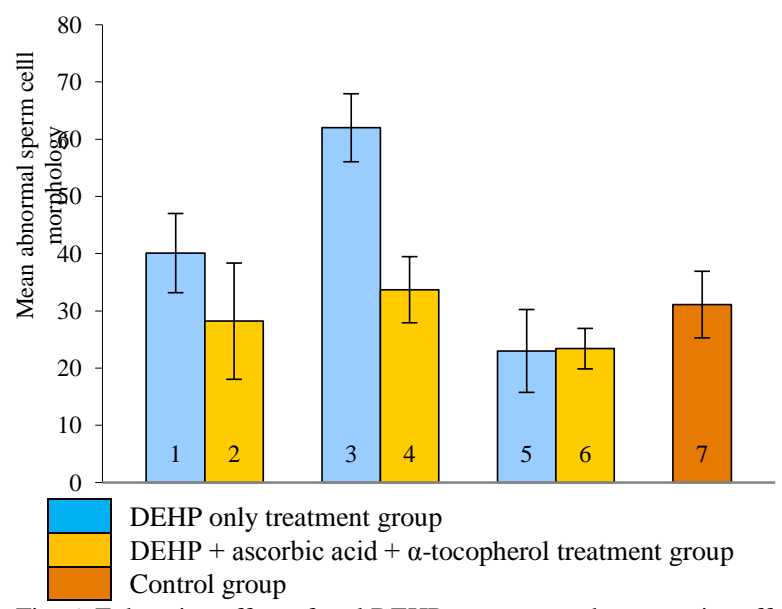

Fig. 6. Enhancing effect of oral DEHP exposure and suppressive effect of oral ascorbic acid and $\alpha$-tocopherol on abnormal sperm morphology in adult Wistar rats.

\section{Serum Testosterone Concentration}

In Fig. 7, mean serum testosterone concentration in groups 1, 2 and 3 treated with oral DEHP only were $12.92 \pm 1.52 \mathrm{ng} / \mathrm{mL}, 9.56 \pm 1.34 \mathrm{ng} / \mathrm{mL}$ and $12.15 \pm 2.04 \mathrm{ng} / \mathrm{mL}$ respectively, reflecting a significant reduction $(\mathrm{p}<0.05)$ only in group 2 compared to $12.56 \pm 0.82 \mathrm{ng} / \mathrm{mL}$ Co-treatments with oral AA and $\alpha$-TCP numerically, but insignificantly increased the serum testosterone concentration in groups 4 and $6(15.06 \pm 1.13 \mathrm{ng} / \mathrm{mL}$ and $12.73 \pm 1.67 \mathrm{ng} / \mathrm{mL})$, but did significantly increased $(\mathrm{p}<0.05)$ the value in group 5 $(10.17 \pm 0.54 \mathrm{ng} / \mathrm{mL})$ compared to the Control group value. This implies that oral DEHP exposure reduces serum testosterone concentration; while co-treatments with oral AA and $\alpha$-TCP prevent this suppressive effect of DEHP on serum concentration.

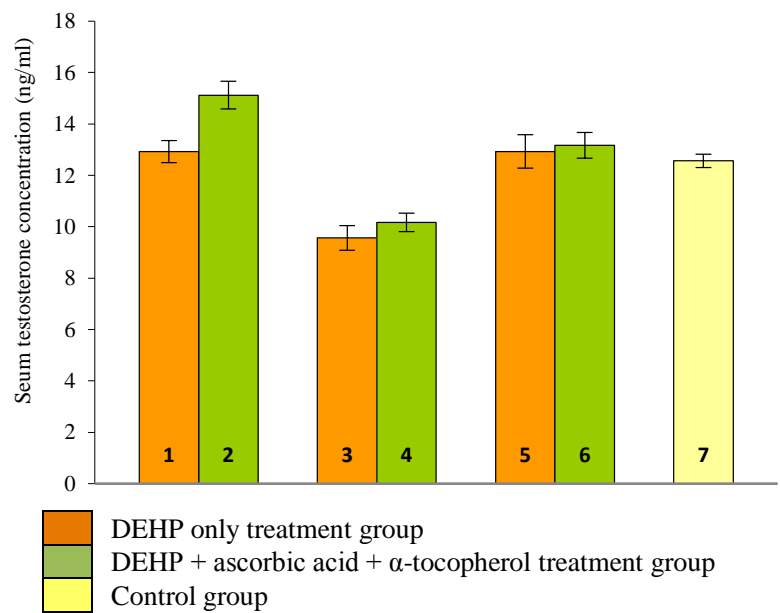

Fig. 7. Suppressive effect of oral DEHP exposure and enhancing effect of oral ascorbic acid and $\alpha$-tocopherol on Serum testosterone concentration in adult Wistar rats. 


\section{E. Serum Super oxide dismutase concentration}

At the end of treatments, the mean serum SOD level (units $/ \mathrm{mL}$ ) were $0.055 \pm 0.010,0.048 \pm 0.010$ and $0.017 \pm 0.000$ in experimental groups 1,2 and 3, while in groups 4,5 and 6 , the SOD levels were $0.068 \pm 0.010,0.064 \pm 0.010$ and $0.059 \pm 0.010$ respectively (Fig. 8). Comparing between treatment blocks, there significant increases $(p<0.05)$ in groups with the antioxidants treatment compared to the corresponding groups with DEHP only treatment. However, comparing with the Control group value of $0.076 \pm 0.010$ units $/ \mathrm{mL}$, significant reductions $(\mathrm{p}<0.05)$ were observed in groups 1, 2, 3 and 6 , but no significant difference was obaserved in groups 2 and 3 respectively. These findings imply that while oral DEHP treatments reduces serum SOD levels (an indication of oxidative stress), oral AA and $\alpha$-TCP restores serum SOD level to normal serum levels in dose dependent manner, thereby offering oxidative protection against DEHP effects.

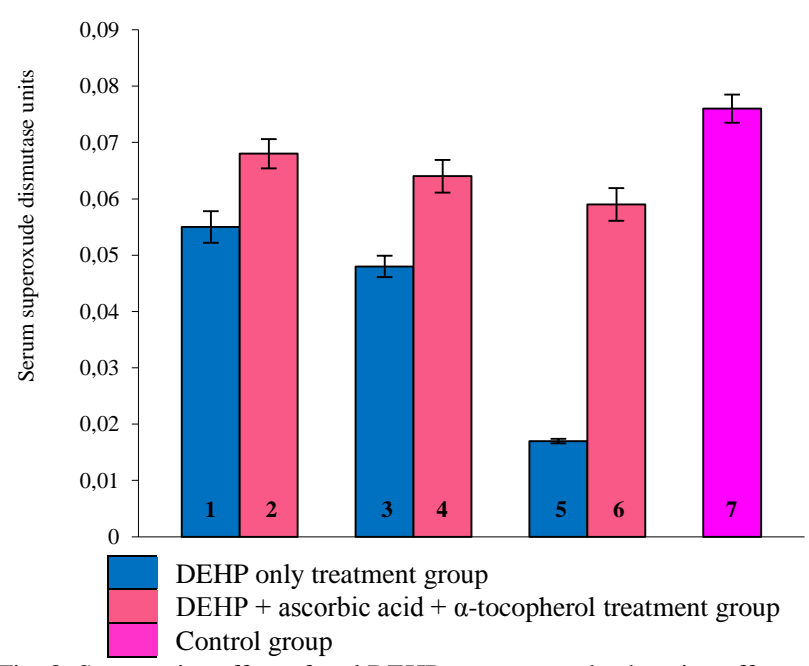

Fig. 8. Suppressive effect of oral DEHP exposure and enhancing effect of oral ascorbic acid and $\alpha$-tocopherol on serum Super oxide dismutase concentration in adult Wistar rats.

\section{DISCUSSION}

Exposure to DEHP, classified as EP, directly impairs spermatogenesis through the induction of generate oxidative stress in the gonads [24]. In the present study, findings showed significant changes in semen parameters (sperm count, motility and morphology) as well as serum testosterone concentration and SOD units upon exposure to DEHP. The semen parameters of sperm count, sperm motility (total and active) as well as normal sperm morphology were significantly reduced with an associated inverse increases in sluggish sperm motility and abnormal sperm morphology. This clearly demonstrated the negative impact of exposure to oral DEHP on male gonadic functions. DEHP possesses the potential to induce oxidative stress in the male gonads by generating high levels of ROS [24], [39], [40]. This may underscore the gonadotoxicity for which DEHP has been known for [11]. The study by Ogli et al. [12] supported our findings as it showed clear evidence of cellular disruption in the testes of male Wistar rats exposed to DEHP, resulting in semen profile and testicular histological derangements.

The observed serum testosterone concentration reduction with exposure to oral DEHP in this study is consistent with findings in previous studies which have demonstrated severally that exposure to DEHP in varying doses suppressed both testicular and basal serum concentrations of testosterone with no effect on gonadotropins [41], [42]. DEHP induced oxidative stress in testes is associated with decreased testosterone levels as well as increased incidence of multinucleated gonocytes (spermatocytes) in seminiferous cords [43], [44] due to the fact that ROS directly cause defects spermatozoa DNA formation, targeting JAZF1, TR4, Sperm 1, and Cyclin A1 genes. It has been shown that spermatogenesis is sustained, among other factors, by high intratesticular testosterone concentration arising from its sequestration by Sertoli cells (SCs). The precise mechanism for this sequestration remains a subject of studies [45]. To maintain such high level of testosterone production however, Leydig cell (LC) must have abundant supply of cholesterol, which can either be imported from the extracellular space or synthesized intracellularly from lipids. Inhalational DEHP exposures of pre-pubertal female rats have been shown to decrease serum cholesterol level in adulthood [46]. This suppression of serum cholesterol, and consequently, serum testosterone concentrations may be related to the ability of DEHP to preferentially and selectively target Scarb1 and Star genes involved in transporting cholesterol on the one hand and Cyp11a1 gene (also known as P450scc, Hsd3b1, and Cyp17a1) involved in converting cholesterol to testosterone on the hand. These genes are involved in pathways that directly and indirectly affect testosterone production by the LCs as well as those that may be essential in the role testosterone plays in the normal interaction and development between SCs and the maturing spermatocytes. Targeting these genes therefore, may impair these pathways and consequently negatively affect smooth spermatogenesis.

While the precise factor or factors that initiate and drive fetal LC testosterone production are not known, there are a number of factors that can either induce or inhibit LC testicular testosterone production. Some of these factors are altered in expression following exposure to toxic phthalates such as low serum testosterone concentration been induced by inhibition of testosterone production in the testes by angiotensin and vasopressin under induction by DEHP. DEHP and phthalates in general induces this dual angiotensin and vasopressin receptor (Nalp6), (together with aminopeptidase A, an enzyme responsible for converting angiotensin II to angiotensin III) in the testes [47]. Depressed serum and particularly testicular testosterone concentrations are consequentially deleterious to the process of spermatogenesis as these have been associated with the detachment of developing spermatids, especially between steps 7-8 of spermatogenesis from the SCs, thereby halting spermatogenesis during the process of meiosis. The inadequacy of testosterone sequestration in the testes is due to failure of SCs to produce the adhesion molecule $\mathrm{N}$ cadherin, the production of which appears to require both FSH and testosterone. Furthermore, the formation of blood testes barrier (BTB) is compromised resulting in the premature displacement of immature germ cells from the SCs on the one hand, and the inability of mature spermatozoa to be released from the SCs on the other hand. 
Thus, the DEHP induced suppression of testosterone concentration in exposed rats may be due to interference in the process of steroidogenesis in testicular cells owing to the oxidative stress generated in the cells, impacting negatively on quantitative, qualitative and functional spermatogenesis as observed in the current study.

Serum SOD levels may be a useful marker of tissue oxidative stress linked to activities of peroxisome proliferator. Serum SOD level is related to reactive oxygen specie (ROS) index in an inverse proportionality; a reduction in the former is associated with a rise in the latter. Earlier, the works of [48] and that of [49] did show that the induction of oxidative stress in tissues is associated with reduction in levels of SOD. The work of these authors and recently, that of [39] are clearly consistent with the findings of our study where the reduction in serum SOD level was significant with oral DEHP exposure in a dose related manner. DEHP or its metabolite MEHP, induces the proliferation of peroxisome, a process resulting in the possibility of enhanced production of ROS which are chemically reactive chemical species containing oxygen such as the hydrogen peroxides $\left(\mathrm{H}_{2} \mathrm{O}_{2}\right)$, superoxides $\left(\mathrm{O}_{2}-\right)$, hydroxyl radicals $(\mathrm{OH}-)$, singlet oxygen radical $(\mathrm{O}-)$. In the body, though ROS are formed as a natural by product of normal oxidative metabolic process which play important role in cell signaling and homeostasis. ROS levels can increase significantly, resulting in significant damage to cell structures. Cumulatively, this is known as oxidative stress. ROS freely donate an oxygen radical, thereby acting as powerful oxidants. Most body cells, and spermatozoa particuarly, are susceptible to the activities of oxidants (in oxidative stress) since their membranes posses high amounts of polyunsaturated fats which can easily be rendered unusable when oxidized into saturated fats. Activities of cells generally are dependent on functional cell membrane.

The levels of these radical generated in the body are kept at acceptable (useful) levels by a group of scavengers known as cellular antioxidant enzymes which include SOD, peroxidases (gluthatione proxidase especially), reductases and catalase amongst others. SOD is associated with a host of activities in the human body, especially that which is responsible for mopping up of oxidizing radicals like ROS with attendant significant reduction of the serum level of the enzyme [38]. The activities of SOD are linked to the activities of peroxisome proliferator-activated receptors (PPARs). There is a positive correlation between PPAR protein expression and SOD activity in tissues [50]. The main physiological role of PPARs is to transform various environmental, nutritional or inflammatory stimuli into intracellular signals that regulate lipid metabolism, cell proliferation and differentiation. DEHP alters the transactivation of $\alpha$ subunit of PPAR leading to induction of subsequent transcriptional changes with a broad range of effects on reproductive cell function [51].

In the present study, all observed derangements in semen parameters, serum testosterone concentration, and serum SOD levels were significantly improved in varying degrees with the co-administration of oral AA and $\alpha$-TCP. These findings are supported by those of [24] and [25], amongst others. Since these outcomes were observed in the presence of concurrent DEHP administration with the vitamins, it is therefore, an indication that the induction of oxidative stress by DEHP was effectively counteracted by these antioxidants. In other words, these exogenous antioxidants substantially strengthened the body's antioxidant machinery evidenced by the was marked improvement of serum SOD. It may be stated therefore, that these antioxidants have a therapeutic/protective effect on DEHP-induced oxidative derangements in the male reproductive system. These antioxidants exert their beneficial action by acting as cofactor in several vital enzymatic reactions, acting as a substrate for ascorbate peroxidase, as well as an enzyme cofactor for the biosynthesis of many important biochemicals. AA is known to act as an electron donor for eight different enzymes [52] and assisting in the formation of wide spectrum of biochemicals like hormones, enzymes, proteins, neurotransmitters, ribo- and deoxyribonucleic acids (RNA and DNA) in cells. Specifically, it donates an electron to ROS to form monodehydroascorbate and then subsequently to dehydroascorbate as itself is reduced to water. The oxidized form of ascorbate is relatively stable and unreactive, and does not cause cellular damage [53]. $\alpha$ TCP on the other hand, is known to neutralize free radicals very effectively and when it does this, its molecule is altered in such a way that its antioxidant capacity is lost. However, working with other antioxidants such as AA, glutathione, selenium and vitamin B3, the antioxidant capacity of $\alpha$-TCP is regenerated [54], thereby prolonging, sustaining and rendering $\alpha$-TCP antioxidant actions more efficient. The studies done by [23] and [55] suggested that antioxidants act best when co-administered as they exhibit synergy in their actions to confer protection from environmental pollutants/toxins that inflict cellular injuries. In this way, AA and $\alpha$-TCP, acting together, effectively reversed the DEHP induced derangements observed in our study.

\section{CONCLUSION}

The study has shown that oral exposure to DEHP impacts negatively on the qualitative, qualitative and functional characteristics of semen as well as the circulation of male reproductive hormone while co-exposure with antioxidants AA and $\alpha$-TCP ameliorates these derangements, thus protecting cells from DEHP induced cellular toxicity, reenforcing the body's natural antioxidant and capability and preserving the normal physiological state/functions of these cells.

\section{RECOMMENDATION}

Arising from the findings of this study, we recommended that attempts should be made in reducing exposure of humans of all ages to DEHP by de-emphasising dependence on use of plasticized PVC materials, especially for domestic and medical purposes. We equally recommend the adoption more use of non-plasticized PVC as well as organic materials for aforementioned purposes while equally emphasizing the daily intake of AA and $\alpha$-TCP as daily supplements to mitigate the effects of oxidants present in the environment. 


\section{LIMITATIONS}

Even though the study was well designed to satisfy the overall aim, the study was limited in scope owing to paucity of funds.

\section{ACKNOWLEDGMENT}

The authors wish to acknowledge the contributions of the Technical staff , namely Mr. Richard Ediale and Mr. Gabriel Odugbo of Physiology department as well as Mr Emmanuel Ogbe and Mr Pious Enokela of Medical biochemistry and Pharmacology departments respectively, all of College of Health Sciences, Benue state University Makurdi for their technical assistance in running the semen analysis, serum SOD and testosterone assays.

\section{CONFLICT OF INTERESTS}

We the authors hereby declare that this original work has not been previously published, nor is it before another journal for consideration.

\section{REFERENCES}

[1] Jensen, T. K., Sobotka, T., Hansen, M. A., Pedersen, A. T., Lutz, W., Skakkebaek, N. E.. (2008). Declining trends in conception rates in recent birth cohorts of native Danish women: a possible role of deteriorating male reproductive health. International Journal of Andrology 31(2): 81-92.

[2] Agarwal, A., Mulgund, A., Hamada, A., \& Chyatte, M. R. (2015). A unique view on male infertility around the globe. Reproductive Biology and Endocrinology: RB\&E, 13, 37. http://doi.org/10.1186/s12958-015-0032-1

[3] WHO. Infecundity, infertility, and childlessness in developing countries. DHS Comparative Reports No 9. Calverton, Maryland, USA. 2004 ORC Macro and the World Health Organization.

[4] Sundby, J., Mboge, R., \& Sonko, S. (1998). Infertility in the Gambia: frequency and health care seeking. Social Sciences and Medicine, 46, 91-99.

[5] Geelhoed, D. W., Nayembil, D., Asare, K., S., van Leeuwen, J., H., \& Roosmalen, J. (2002). Infertility in rural Ghana. International Journal of Gynaecology and Obstetrics, 79, 137-142.

[6] Haile, A. (1990). Fertility conditions in Gondar, northwestern Ethiopia: an appraisal of current status. Studies in Family Planning, 21, 110-118.

[7] Adeniji, R. A., Olayemi, O., Okunlola, M.A., \& Aimakhu, C.O. (2003). Pattern of semen analysis of male partners of infertile couples at the University College Hospital, Ibadan. West African Journal of Medicine, 2003; 22: 243-245.

[8] Uadia, P. O., \& Emokpae, A. M. (2015). Male infertility in Nigeria: A neglected reproductive health issue requiring attention. Journal of Basic and Clinical Reproductive Science. 2015; 4(2): 45-55.

[9] Panti. A. A., \& Sununu, Y. T. (2014). The profile of infertility in a teaching Hospital in North West Nigeria. Sahel Medical Journal, 17: 7-11..

[10] Sokol, Z. R., Kraft, P., Fowler, I. M., Mamet, R., Kim, E., \& Berhane, K. T. (2006). Exposure to environmental Ozone alters semen quality. Environmental Health Perspectives, 114(3), 360-365.

[11] Baralić, K., Buha Djordjevic, A., Živančević, K., Antonijević, E., Anđelković, M., Javorac, D., Ćurčić, M., Bulat, Z., Antonijević, B., \& Đukić-Ćosić, D. (2020). Toxic Effects of the Mixture of Phthalates and Bisphenol A-Subacute Oral Toxicity Study in Wistar Rats. International journal of environmental research and public health, 17(3), 746. https://doi.org/10.3390/ijerph17030746

[12] Ogli, S. A., Odeh, S. O., \& Egesie, G. U. (2019). Gonadotoxic Potentials of Di- (2-Ethyl Hexyl) Phthalate in the Adult Male Wistar Rats. Journal of Research in Basic Clinical Sciemce, 2: 163-171.

[13] Telisman, S., Cvitkovic, P., Jurasovic, J., Pizent, A., Gavella, M., \& Rocic, B. (2001). Semen quality and reproductive endocrine function in relation to biomarkers of lead, cadmium, zinc, and copper in men. Environmental Health Perspectives, 108, 45-53.

[14] Ma, T., Zhou, W., Chen, L., Wu, L., Christie, P., Zhang, H., et al. (2017) Toxicity effects of di-(2-ethylhexyl) phthalate to Eisenia fetida at enzyme, cellular and genetic levels. PLOS ONE 12(3): 1-12. e0173957. https://doi.org/10.1371/journal

[15] Food and Drug Administration (FDA) (2002). Public health notification: PVC devices containing the plasticizer DEHP, US. FDA. Center for Devices and Radiological Health. Retrieved June 10th, 2006 from: https://www.fda.gov/cdrh/safety/dehp/html.

[16] Quinnies, K. M., Harris, E. P., Snyder, R. W., Sumner, S. S., \& Rissman, E. F. (2017). Direct and transgenerational effects of low doses of perinatal di-(2-ethylhexyl) phthalate (DEHP) on social behaviors in mice. PLOS ONE, 12(2), e0171977. https://doi.org/10.1371/journal.pone.0171977

[17] Ge, R., Chen, G., Dong, Q., Akingbemi, B., Sottas, C. M., Santos, M. Sealfon, S. C., Bernard, D. J., \& Hardy, M. P. (2007). Biphasic Effects of postnatal exposure to Diethylhexylphthalate on the timing of puberty in male Rats. Journal of Andrology, 28(4), 513-520.

[18] Hansen, C., Luben, T. J., Sacks, J. D., Olshan, A., Jeffay, S., Strader, L., \& Perreault, S. D. (2010). Effect of ambient air pollution on sperm quality. Environmental Health Perspectives, 118(2), 203-209.

[19] Dai, X., Zhang, Q., Yu, Y, Sun, W., Wang, R., \& Miao, D. (2018). Bmi1 Deficient Mice Exhibit Male Infertility. International Journal of Biological Sciences, 14(3), 358-368.

[20] Petroianu, A., \& Alberti, L. R. (2011). Effect of oral supplementation of vitamin $\mathrm{C}$ on intestinal anastomotic resistance. Revista do Colegio Brasiliero de Cirurgioes, 38(1), 54-58

[21] Heinrich, U. R., Fischer, I., Brieger, J., Rümelin, A., Schmidtmann, I., Li, H., Mann, W. J., \& Helling, K. (2008). Ascorbic acid reduces noise-induced nitric oxide production in the guinea pig ear. Laryngoscope, 118(5), 837-842.

[22] Takhshid, M. A., Tavasuli, A. R., Heidary, Y., Keshavarz, M., \& Kargar, H. (2012). Protective Effect of Vitamins E and C on Endosulfan-Induced Reproductive Toxicity in Male Rats. Iranian Journal of Medical Sciences, 37(3), 173-180.

[23] Ogli, S. A., Ochalefu, D. O., \& Ojabo, C. O. (2011). Effects of oral supplements regime of vitamins $\mathrm{C}$ and $\mathrm{E}$ on sperm count in Wistar rats. Journal of Medicine in the Tropics, 13, 50-53.

[24] Tang, X., Wu, S., Shen, L., Wei, Y., Cao, X., Wang, Y., Long, C., Zhou, Y., Li, D., Huang, F., Liu, B., \& Wei, G. (2018). Di-(2ethylhexyl) phthalate (DEHP)-induced testicular toxicity through Nrf2-mediated Notch1 signaling pathway in Sprague-Dawley rats. Environmental Toxicology, 33(7), 720-728

[25] Adewoyin, M., Ibrahim, M., Roszaman, R., Md Isa, M. L., Mat Alewi, N. A., Abdul Rafa, A. A., \& Anuar, M. N. N. (2017). Male Infertility: The Effect of Natural Antioxidants and Phytocompounds on Seminal Oxidative Stress. Diseases, 5(1), 9. http://doi.org/10.3390/diseases5010009.

[26] Rajesh, P., Sathish, S., Srinivasan, C., Selvaraj, J., \& Balasubramanian, K. (2013). Phthalate is associated with insulin resistance in adipose tissue of male rat: role of antioxidant vitamins. Journal of Cellular Biochemistry, 114(3), 558-569.

[27] Animal Environment, Housing, and Managements (1996). In: D Clark (Rev). Guide for the Care and Use of Laboratory Animals (pp. 21-25). Washington, DC: The National Academies Press.

[28] Takano, H., Yanagisawa, R., Inoue, K. I., Ichinose, T., Sadakano, K. \& Yoshikawa, T. (2006). Di-(2-ehylhexyl) Phthalate enhances atopic dermatitis-like skin lesions in Mice. Environmental Health Perspectives, 114, 1266-1269.

[29] Badr, G., Bashandy, S., Ebaid, H., Mohany, M., \& Sayed, D. (2012). Vitamin C supplementation reconstitutes polyclonal $\mathrm{T}$ cells in streptozotocin-induced diabetic rats. European Journal of Nutrition, 52(5), 623-633.

[30] Petroianu, A., \& Alberti, L. R. (2011). Effect of oral supplementation of vitamin $\mathrm{C}$ on intestinal anastomotic resistance. Revista do Colegio Brasiliero de Cirurgioes, 38(1), 54-58.

[31] Krishnamoorthy, G., Venkataraman, P., Arunkumar, A., Vignesh, R. C., Aruidhas, M. M., \& Arunakaran, J. (2007). Ameliorative effect of vitamins ( $\alpha$-tocopherol and ascorbic acid) on PCB (Aroclor 1254) induced oxidative stress in rat epididymal sperm Reproductive Toxicology, 23(2), 239-245.

[32] Biswas, A., Mohan, J., Sastry, K. V., \& Tyagi, J. S. (2007). Effectiveness of dietary vitamin $\mathrm{E}$ on the cloacal gland, foam and semen characteristics of male Japanese quail. Theriogenology, 67(2), 259-263.

[33] University of Delaware, Office of Laboratory Animal Medicine. Cardiac puncture blood collection (Terminal Procedure) SOP \#PRO002. Rev.May 2010. Rerieved on May 20th, 2011 from: http://www.udel.edu/research/pdf/Cardiac-Puncture-BloodCollection-Terminal.pdf.

[34] Cheesbrough M. (2000). Examination of semen. District Laboratory Practice in Tropical Countries (2nd Low price. ed., part II). 2000; pp. 130-132. Cambridge UK; University press. 
[35] Sikka, S. C., Hellstrom, W. J. (2016). Current updates on laboratory techniques for the diagnosis of male reproductive failure. Asian Journal of Andrology, 18(3): 392-401.

[36] Van Haaster, L. H., \& de Rooij, D. G. (1993). Spermatogenesis is accelerated in the immature djungarian and chinese hamster and rat. Biology of Reproduction, 49, 1229-1235.

[37] Marklund, S., \& Marklund, G. (1974). Involvement of the Superoxide Anion Radical in the Autoxidation of Pyrogallol and a Convenient Assay for Superoxide Dismutase European Journal of Biochemistry, 47, 469-474.

[38] Gavali, Y., Deore, D., Surwase, S. P., \& Zingade, U. (2013). Study of the serum superoxide dismutase levels in smoking and non-smoking patients with COPD. International Journal of Recent Trend in Science and Technology, 5(3), 121-126.

[39] Wu, M., Xu, L., Teng, C., Xiao, X., Hu, W., Chen, J., \& Tu, W. (2019). Involvement of oxidative stress in di-2-ethylhexyl phthalate (DEHP)-induced apoptosis of mouse NE-4C neural stem cells. Neurotoxicology, $70, \quad 41-47$. https://doi.org/10.1016/j.neuro.2018.10.013

[40] Erkekoglu, P., Giray, B., Rachidi, W., Hininger-Favier, I., Roussel, A. M., Favier, A., \& Hincal. F. (2011). Effects of di(2ethylhexyl)phthalate on testicular oxidant/antioxidant status in selenium-deficient and selenium-supplemented rats. Environmental Toxicology, 10, 1002.

[41] Culty, M., \& Thuillier, R., Li, M., Wang, Y., Martinez-Arguelles, D. B., Benjamin, C. G., et al. (2008). In Utero exposure to Di-(2ethylhexyl) phthalate exerts both short-term and long-lasting suppressive effects on testosterone production in the Rat. Biology of Reproduction, 78(6):1018-1028, https://doi.org/10.1095/biolreprod.107.065649.

[42] Oishi, S., \& Hiraga, K. (1980). Testicular atrophy induced by phthalic acid monoesters: effects of zinc and testosterone concentrations. Toxicology, 15, 197-202

[43] Shi, Y. Q., Fu, G. Q., Zhao, J., Cheng, S. Z., Li, Y., Yi, L. N., Li, Z. Zhang, L., Zhang, Z. B., Dai, J., \& Zhang, D. Y. (2019). Di(2ethylhexyl) phthalate induces reproductive toxicity via JAZF1/TR4 pathway and oxidative stress in pubertal male rats. Toxicology and

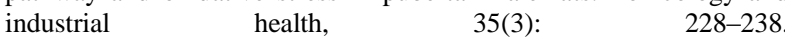
https://doi.org/10.1177/0748233718824911

[44] Botelho, G. G., Bufalo, A. C., Boareto, A. C., Muller, J. C., Morais R. N., Martino-Andrade, A. J., et al. (2009). Vitamin C and resveratrol supplementation to rat dams treated with $\operatorname{di}(2$ ethylhexyl)phthalate: impact on reproductive and oxidative stress end points in male offspring. Archives of Environmental Contamination and Toxicology.9; 57(4):785-793

[45] Gill-Sharma, M. K. (2018). Testosterone Retention Mechanism in Sertoli Cells: A Biochemical Perspective. The Open Biochemistry Journal, 12: 103-112.

[46] Ma T, Zhou W, Chen L, Wu L, Christie P, Zhang H, et al. (2017) Toxicity effects of di-(2-ethylhexyl) phthalate to Eisenia fetida at enzyme, cellular and genetic levels. PLOS ONE; 12(3): 1-12. e0173957.

[47] Leung, P. S., Sernia C. (2003). The renin-angiotensin system and male reproduction: new functions for old hormones. Journal of Molecular Endocrinology, 30; 263-270.

[48] Elliott, B. M., \& Elcombe, C. R. (1987). Lack of DNA damage or lipid peroxidation measured in vivo in the rat liver following treatment with peroxisomal proliferators. Carcinogenesis, 8, 12131218.

[49] Orbea, A., Ortiz-Zarragoitia, M., \& Cajaraville, M. P. (2008). Interactive effects of benzo(a)pyrene and cadmium and effects of di(2-ethylhexyl) phthalate on antioxidant and peroxisomal enzymes and peroxisomal volume density in the digestive gland of mussel Mytilus galloprovincialis Lmk. Journal of Biomarkers, 7(1), 33-48.

[50] Gong, P., Xu, H., Zhang, H., \& Wang, Z. (2012). PPAR expression and its association with SOD and NF- $\mathrm{BB}$ in rats with obstructive jaundice. Biomedical Research-India, 23(4), 551-560.

[51] Ernst, J., Jann, J. C., Biemann, R., Koch, H. M., \& Fischer, B. (2014). Effects of the environmental contaminants DEHP and TCDD on estradiol synthesis and aryl hydrocarbon receptor and peroxisome proliferator-activated receptor signalling in the human granulosa cell line KGN. Molecular Human Reproduction, 9, 919-928.

[52] Levine, M., Rumsey, S. C., Wang, Y., Park, J. B., \& Daruwala, R. (2000). Vitamin C. In M. H. (Ed.), Biochemical and physiological aspects of human nutrition pp 541-567. Philadelphia: W B Saunders.

[53] Juan, M. C., Alicia, P., Oriana, B., Bing, Z., Roberto, S., \& David, W. G. (2004). Vitamin C is a kinase inhibitor. Molecular and Cellular Biology, 24(15), 6645-6652.

[54] Traber, M. G., \& Atkinson, J. (2007). "Vitamin E, antioxidant and nothing more". Free Radical Biology and Medicine, 43(1), 4-15.
[55] Yarube, S. U., Ayo, J. O., \& Fatihu, M. Y. (2014). Harmful effects of ascorbic acid and $\alpha$-tocopherol on male reproductive organs of rats chronically exposed to sodium nitrate. Journal of Medicine in the Tropics, 16(1), 5-8. 